\title{
MONITORING RECYCLED WATER INJECTION INTO A CONFINED AQUIFER IN SINDOS (THESSALONIKI) USING ELECTRICAL RESISTIVITY TOMOGRAPHY (ERT): INSTALLATION AND PRELIMINARY RESULTS
}

\author{
Tsourlos P. ${ }^{1}$, Vargemezis G. ${ }^{1}$, Voudouris C.
Stampolidis A. \\ ${ }^{1}$ Aristotle University of Thessaloniki, School of Geology, Department of Geophysics, \\ tsourlos@geo.auth.gr,varge@geo.auth.gr \\ ${ }^{2}$ Aristotle University of Thessaloniki, School of Geology, Department of Geology, \\ kvoudour@geo.auth.gr \\ ${ }^{3}$ Thessaloniki Water Supply and Sewerage Co. [E.Y.A.Th S.A.]
}

\begin{abstract}
This work describes the installation and preliminary measurements of an electrical resistivity tomography (ERT) system to monitor the injection of recycled water into a confined aquifer in the area of Sindos. The aim is to provide, through time-lapse electrical resistivity tomography (ERT) measurements and processing, geoelectrical images of rather increased volumetric sampling around and between the holes and to obtain improved understanding of the flow and transport of the injected water.

The details about the general setting and the design of the injection utility are presented and the construction and installation of the ERT cables into the boreholes are explained in full. Preliminary measurements involving single-hole ERT measurements were obtained and processed with a $2 D$ inversion algorithm to produce images of the subsurface. Results depict a very good correlation between ERT images and the lithology logs an indication of the reliability of the approach. This images offer increased resolution and spatial coverage compared to traditional approaches. The entire ERT permanent installation is of low cost, easy to implement and can be used to understand and evaluate the effects of the water injection process.
\end{abstract}

Key words: ERT, single-borehole ERT, water injection, Sindos.

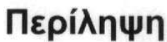

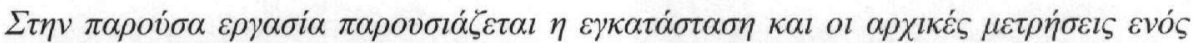

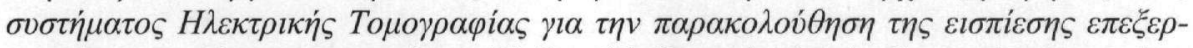

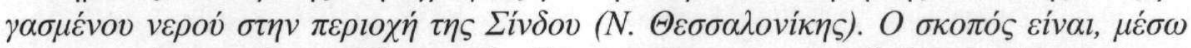

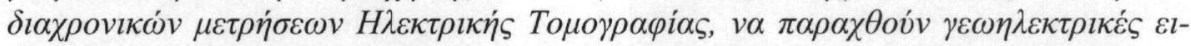

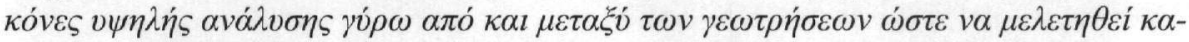

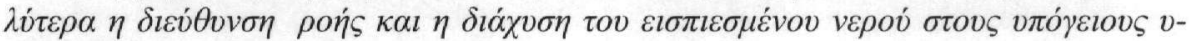

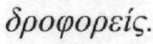

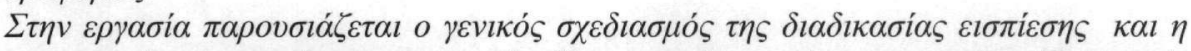

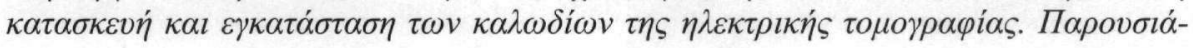




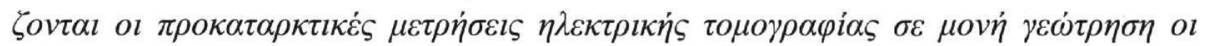

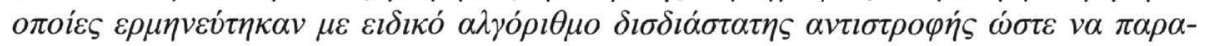

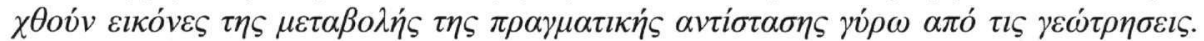

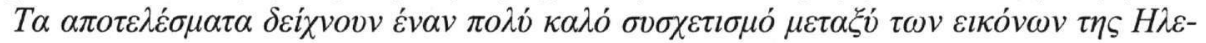

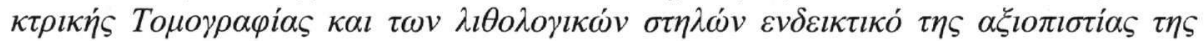

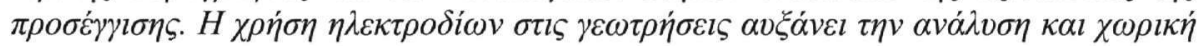

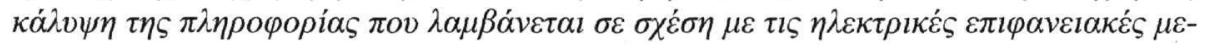

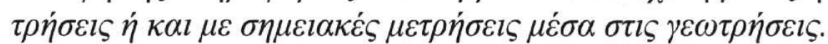

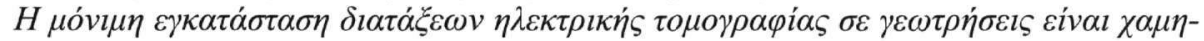

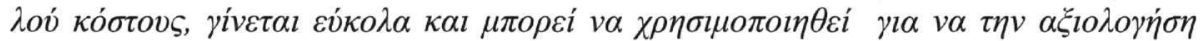

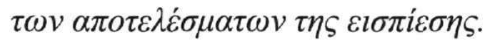

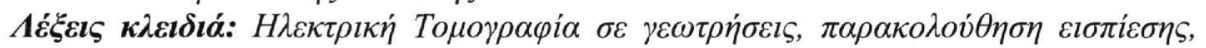

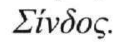

\section{Introduction}

This study was undertaken in support of a larger programme supervised by E.Y.A.Th. and funded by the Greek Ministry of Environment, Physical Planning and Public Works to assess the impact of recycled water injection into a confined aquifer at the Area of Sindos, around $12 \mathrm{Km}$ east to the city of Thessaloniki (Greece) (Fig. 1). The overall aim of this injection process is to improve the quality of a degraded aquifer and increase the groundwater quantity. The project involves the injection of water coming form the Thessaloniki sewage treatment plant after being subjected to tertiary treatment to reach the standards required (viz. potable water) before it is discharged into the ground.

The construction of the injection facility is currently completed and involved the drilling a $100 \mathrm{~m}$ main injection well (P0, Fig. 2) to allow the injection of $13 \mathrm{~m}^{3} / \mathrm{h}$ of recycled water and additional four $100 \mathrm{~m}$ piezometers around it (P1-P4, Fig. 2) to allow the monitoring of the injection process. Standard procedures that were followed before, during and after the drilling involved: (i) preliminary hydrogeological study and surface geophysical survey to position and design the boreholes. (ii) water level monitoring and rock sampling and analysis during the boring (iii) well logging, (iv) analysis of water samples, (v) pumping tests. Currently, permanent monitoring stations are submerged into three of the piezometers to monitor water level, conductivity and $\mathrm{PH}$ before and during the injection process. Further, the systematic chemical analysis of water samples which was initiated before the injection will continue for several months after the injection starts.

Monitoring is a rather essential part in every water injection process (EEA 1996, 1997). Traditional groundwater monitoring relies heavily on "spot" borehole sampling but this approach is often infrequent, and most importantly may not be representative in heterogeneous aquifers. In an attempt to increase the monitoring capabilities of the injection site, permanent in-situ geoelectric sensors were installed in all 5 boreholes. The aim is to provide, through time-lapse electrical resistivity tomography (ERT) measurements and processing, geoelectrical images of rather increased volumetric sampling around and between the holes and to obtain improved understanding of the flow and transport of the injected water. This approach is considered unique and complementary to the traditional monitoring techniques and/or surface or logging geophysical measurements which cannot provide this type of information.

Despite the increased use of time-lapse ERT monitoring the scale and aim of the current setting to monitor recycled water injection has a certain degree of novelty at international level and it is certainly the first time that such a monitoring procedure is used in Greece. The present paper is intended to demonstrate the sensor installation procedure explain the measurement and data analysis approach and to show preliminary field ERT interpreted images which clearly demonstrate the effectiveness and the potentials of the technique. 


\section{Why ERT?}

The Electrical Resistivity Tomography (ERT) technique is currently considered to be one of the most important geophysical tools for imaging the subsurface. The application of ERT has particularly wide use for environmental monitoring involving groundwater exploration, mapping and monitoring salt-water incursion in susceptible aquifers and transport processes of contaminants (LaBrecque 1989, Berryman and Kohn 1990, Ebraheem et al. 1990, Daily et al. 1992, Ramirez et al. 1993, Daily et al. 1995, Dahlin 1996, Park 1998).

Surface ERT imaging in a time-lapse mode, involving permanent electrode installations, has proven to provide in many cases images of larger volumetric scale, in comparison to the standard spot sampling from boreholes and laboratory chemical analysis, which help to recognise and distinguish pollutant transport mechanisms. Several algorithms for inverting time-lapse ERT data have been reported (Loke 1999, LaBrecque and Yang 2002, Kim 2005).

However, as with all surface geophysical methods, spatial resolution decreases with increasing depth of investigation and this can inhibit the detection of small-scale features such as changes in the qualitative and quantitative characteristics of the aquifer. As the major transport mechanisms in groundwater are advection, diffusion, dispersion, absorption, chemical reaction and biodegradation surface standard geophysical methods and water sampling have limited spatial analysis. This limitation can be partially offset by the use of electrodes in boreholes and/or using surface-to-hole configurations. Tsourlos et al. (2003) presented an application of single-hole ERT data for environmental time-lapse monitoring. Several successful applications of the cross-borehole ERT technique have been reported in literature in several fields, including hydrogeological, and environmental monitoring, (Daily and Ramirez 2000, Slater et al. 2000, Goes and Meekes 2004). Further, optimum measuring strategies for the cross-borehole ERT case have been reported by Zhou and Greenhalgh (2000). Several schemes for inverting crosshole or surface-to-borehole data have been reported in the literature (Morelli and LaBrecque 1996, Yi et al. 2003).

One of the constraints of cross-hole ERT is that it cannot be applied in practice when the spacing that exists between adjacent boreholes is wide. In this case the use of single hole-to-surface ERT measurements is an obvious alternative (Asch and Morrison 1989, Bevc and Morrisson 1991, Nimmer and Osiensky 2002, Marescot et al. 2002).

Tsourlos et al. (2004, 2005a, 2005b) examined the case of borehole-to-surface ERT measurements for environmental monitoring and proposed a new algorithm for improved imaging of this type of ERT data.

Thus in the framework of this project ERT spatio-temporal images combined with water quality monitoring in different water levels will promote the understanding and will help to the evaluation of the water injection process.

\section{Geological and Hydrogeological Setting}

The Sindos area is located in the western part of Thermaikos Gulf, North Greece (Fig. 1). The mean annual rainfall is $449 \mathrm{~mm}$ at Sindos rain gauge station. The rainfall occurs mainly from late October to May ( $78 \%$ of annual rainfall).

From a geological point of view, the area is formed of recent unconsolidated material consisting of sands, fine clay to silty sand deposits, which form one multiple aquifer system. Three main aquifers can be identified: one phreatic and two deep confined aquifers. As a result of their origin the deposits are characterized by high degree of heterogeneity and anisotropy.

Groundwater recharge in the aquifer system occurs via the following mechanisms: direct infiltration of rainfall and infiltration through river beds. The direction of groundwater flow is generally from North to South-West. 
The water level within these deposits was at an average depth of about $10-15 \mathrm{~m}$ below ground surface (b.g.s.). The groundwater table is below sea level. There is a small rise trend during the last three years, mainly because of the significant decrease or interruption of the pumping rates from the Thessaloniki Water Supply and Sewerage Company (EYATh).

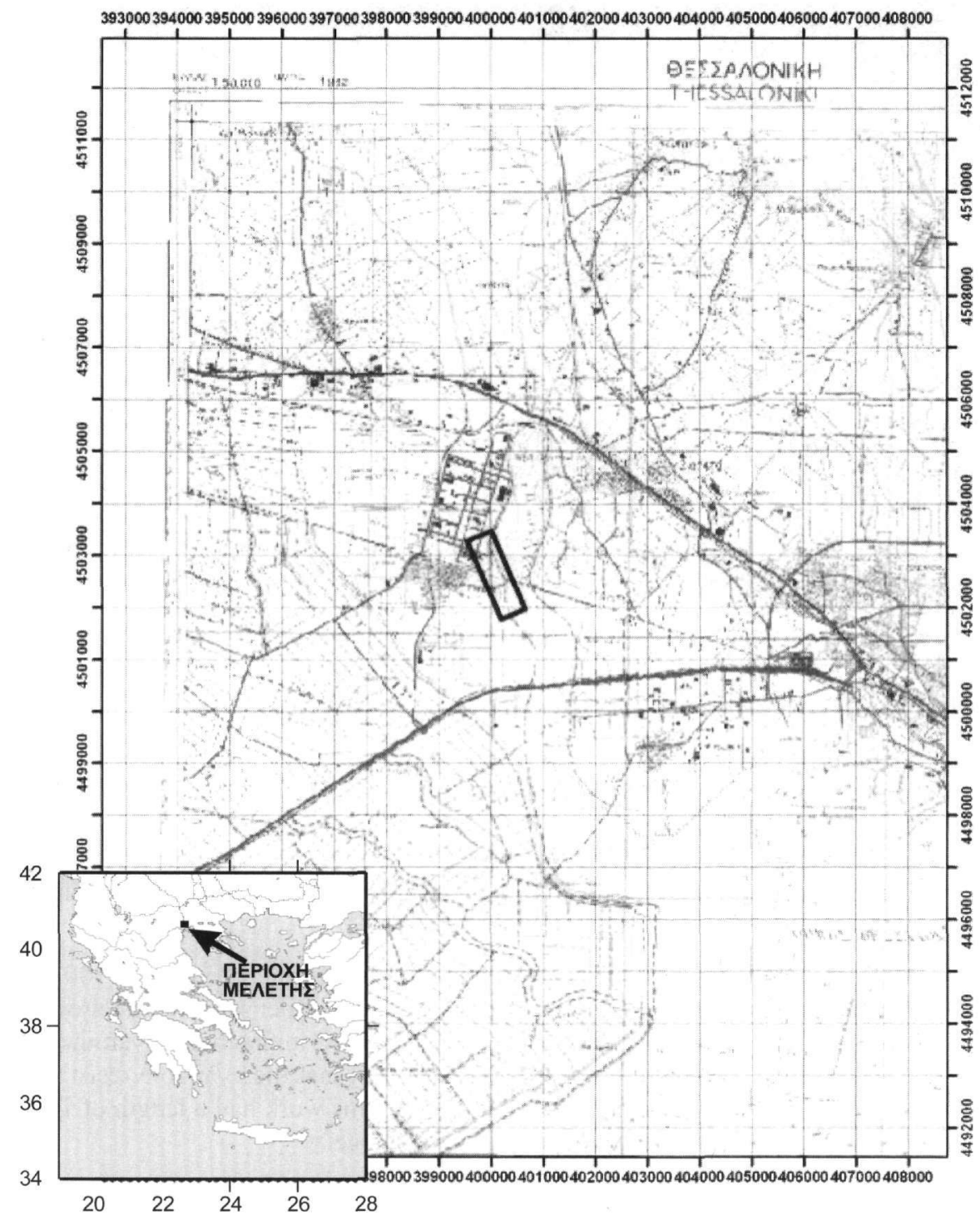

Figure 1 - Location map with the study area marked in black

Based on the results from the conducted pumping test analyses, the mean hydraulic conductivity was estimated to be $\mathrm{k}=6.5 \times 10^{-3} \mathrm{~m} / \mathrm{min}-1.5 \times 10^{-2} \mathrm{~m} / \mathrm{min}$. Transmissivity (T) and Storage coefficient (S) values vary between $\mathrm{T}=5.5 \times 10^{-1}-9.4 \times 10^{-1} \mathrm{~m}^{2} / \mathrm{min}$ and $\mathrm{S}=10^{-3}$, respectively. The presence of silts implies the occurrence of artesian conditions in the area. In the last decades artesian phenomena seized, due to overexploitation.

Conductivity logs from the water wells in the region recorded locally high conductivity values ranging form 900 up to $18000 \mathrm{mS} / \mathrm{cm}$ indicative of the intense salinization problem faced by some of the aquifers. The planned water injection is intended to improve the quality of such aquifers. 


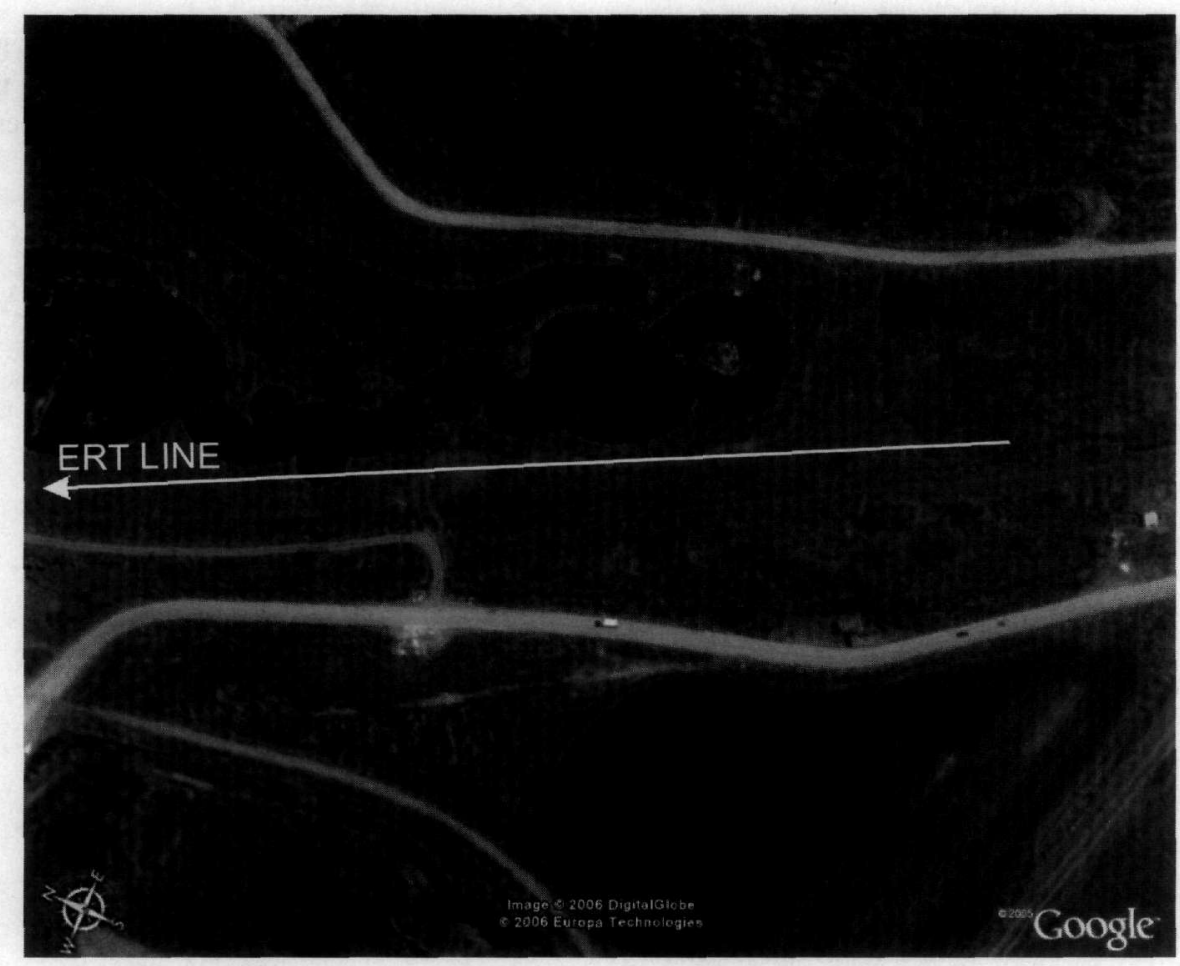

Figure 2 - The water injection installation with injection and monitoring wells (P0, P1-4)

\section{Array Construction and Installation}

In order for borehole ERT measurements to be possible PVC rather than metal casing must be used. Further any metal protective casing commonly used in water wells must be avoided. Yet no other special technical specification as to the construction of the borehole is required. Instrumenting the boreholes to obtain ERT measurements requires the prior construction of special cables and electrodes which are then attached to the borehole's casing during its installation (Fig. 3a).

Given that in our case boreholes were planned to have an approximate length of $100 \mathrm{~m}$, a $3 \mathrm{~m}$ inter-electrode was selected as being the optimum. Even though a denser inter-electrode spacing would allow obtaining higher resolution images it was considered impractical given the increased construction and installation cost and the limited channels (48) that the available resistivity-meter can address. As a result every typical borehole cable used in this work had a length of $110 \mathrm{~m}$ with a total of 36 electrodes spaced $3 \mathrm{~m}$ apart and $5 \mathrm{~m}$ lead-in distance.

Prior experience in installing borehole electrodes involved the use of special flat ribbon multicore cable and stainless steel plates as electrodes (Tsourlos et al. 2003). However, to keep ERT monitoring construction low cost and simple a different design was adopted. The borehole cable was made by assembling 36 standard (easily available and low cost) PVC coated $0.5 \mathrm{~mm}$ cooper conductors of variable length (viz. $5,8,11, \ldots 110 \mathrm{~m}$ for $1^{\text {st }}, 2^{\text {nd }}, 3^{\text {rd }} \ldots 36^{\text {th }}$ electrodes respectively). It follows that the cable has a maximum thickness at its beginning (on the surface) and minimum (1 conductor) at its end.

Preliminary electrode preparation involved stripping the last $2 \mathrm{~cm}$ of every conductor from PVC coating and soldering the copper conductors to avoid possible corrosion (Fig. 3b). Further, each cable end was packed between two adhesive aluminium tape $(4 X 4 \mathrm{~cm})$ pieces which were the folded and glued at their ends with waterproof glue to form electrode (Fig. 3c). 
As the casing was lowered into the hole the cable was simultaneously attached to the casing using tag tapes. For the first 10-15 m of cable installation the entire cable was covered by a line of tag tape to increase mechanical endurance since at this lengths it is particular thin (Fig. 3e). Every three meters the casing lowering procedure was stopped in order to attach an electrode. In order to increase the electrode's effective area, and thus further reduce contact resistance, each electrode was attached to the casing and then was fully covered by a ring of aluminium tag tape $(5 \mathrm{~cm}$ width) which encircled the casing forming in this way a relatively larger electrode (Fig. 3d).

The described procedure proved efficient since it only slightly delayed (approximately $1 \mathrm{~min} /$ electrode) the borehole casing which by the way has to be done fast in order to avoid possible partial collapse of the well walls. At a final stage the space between the borehole and the casing was filled by a gravel filter pack which was inserted slowly in order to avoid possible damages to the cable. Finally a connector was fitted to every conductor (channel) and through a specially constructed box it is possible to connect any or all of the conductors to the automated resistivity instrument's switch box (Fig. 3f).

\section{Single-borehole ERT measurements and interpretation}

The permanently installed cables are planned to be used to obtain cross-hole and surface-to-hole ERT measurements. Yet, at this preliminary stage, extensive repeated tests of the ERT installation have been carried out using single-hole configurations. The aim is to assess the quality of the measurements and further to correlate individual borehole ERT images with the respective lithological columns in order to calibrate interpretations and design future systematic time-lapse ERT measurements which will intensify when the injection procedure starts.

The use of ERT in single boreholes has been previously studied by Tsourlos et al. (2003) and Friedel et al. (2004) who describe the advantages of this approach compared to the standard logging tools. The technique cannot be used for accurate 2D/3D geoelectrical imaging since the electrical current spreads in all directions away from the borehole and the measured apparent resistivities are a kind of "weighted average" of the resistivities of a 3D volume around the hole. With this symmetry there is an infinite combination of resistivity distributions in the volume surrounding the borehole which will produce identical measured datasets. Yet for the case of 1D resistivity models (horizontally stratified earth) this is not a limitation and the inversion scheme will reconstruct accurately (within the resolution limits imposed by the fixed electrode spacing) the subsurface image in this case.

Single-hole ERT measurements can be conducted with any standard geoelectrical array desired (Wenner, Schlumberger, Dipole-Dipole etc.). Yet standard 2D inversion algorithms designed for surface data cannot be used to reconstruct single-hole ERT data since they cannot cope with the borehole electrodes. To deal with this problem a modified interpretation scheme has been proposed by Tsourlos et al. (2003). It is based on a typical iterative smoothness constrained inversion algorithm using a $2.5 \mathrm{D}$ FEM scheme as a forward solver and the scheme makes the assumption that the resistivity perturbation comes from only one side of the borehole (either left or right). This simplification assumes that the opposite side is a layered earth having a resistivity equal to that in the parameter cell adjacent to the borehole. Thus, the layer resistivity changes at every iteration. An example of the applied parameterisation for the case of 10 borehole electrodes is shown in Fig. 4.

Measurements were carried out during several field visits. The recorded contact resistances for the electrodes of all boreholes are very low typically $0.2 \mathrm{KOhm}$ and only the first one or two electrodes which are above the water level (viz. above the depth of $12 \mathrm{~m}$ ) exhibit higher contact resistances (aprox. $10 \mathrm{KOhm}$ ). This fact allowed introducing currents typically higher than 500 $\mathrm{mA}$ and thus good quality measurements with excellent repeatability (low RMS errors) were collected. 
(a)

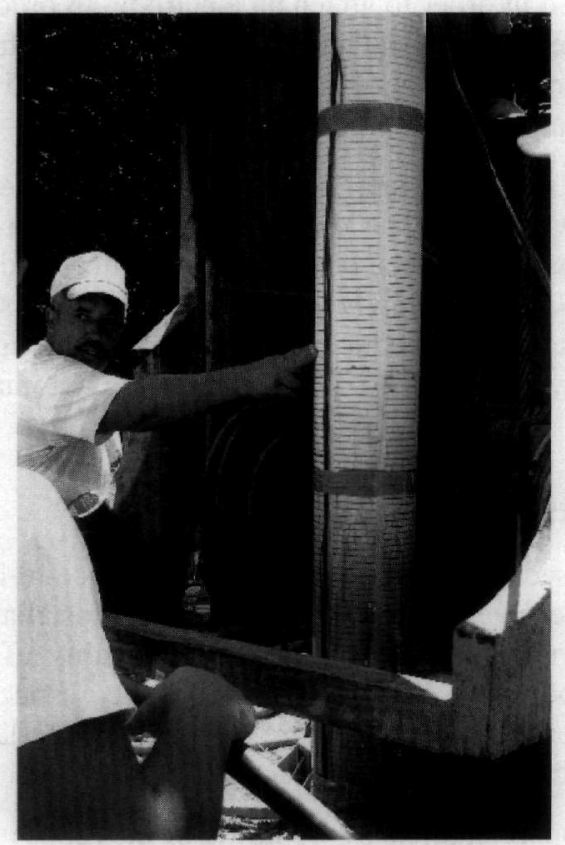

(d)

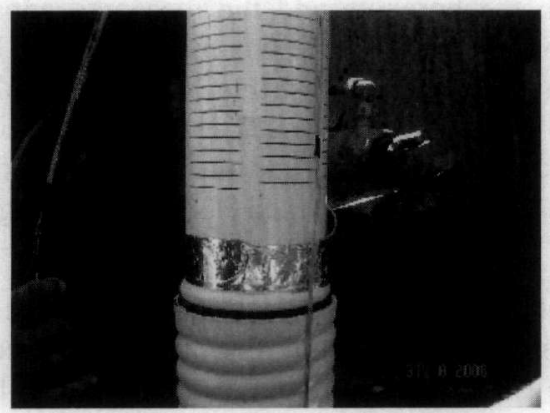

(f)

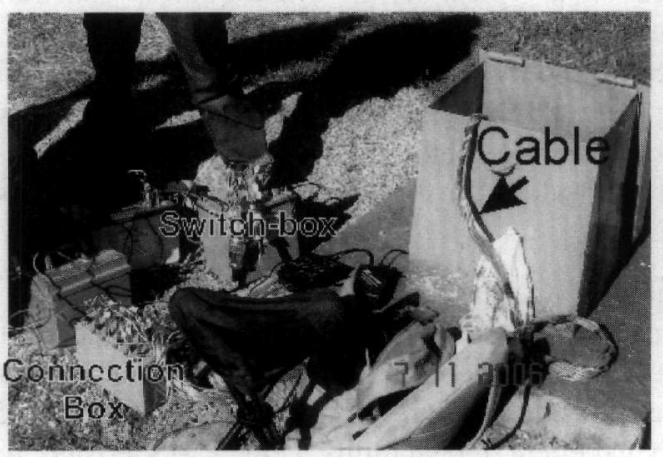

(b)

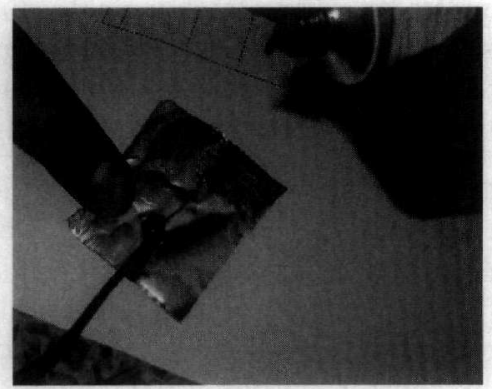

(c)

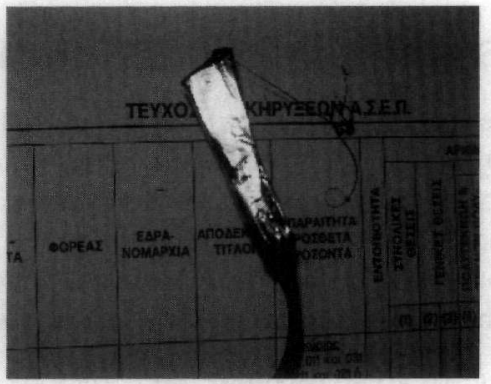

(e)

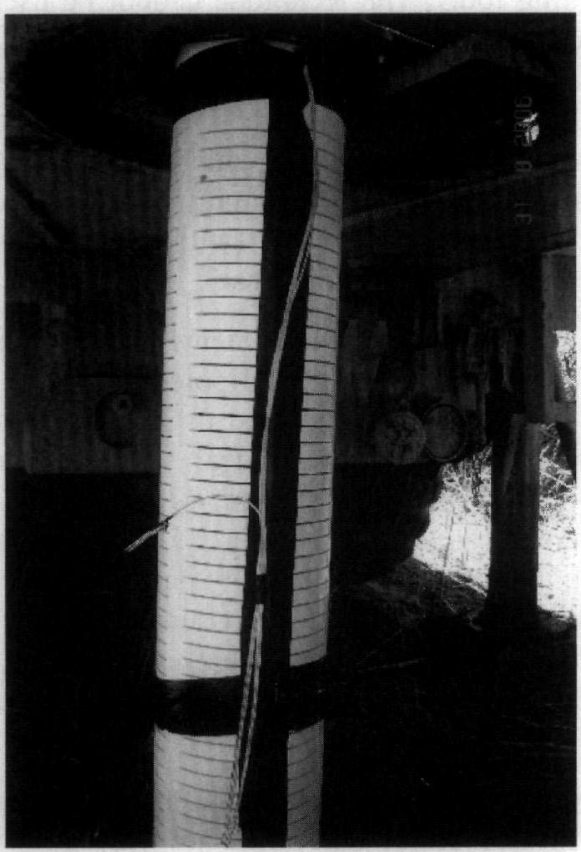

Figure 3 - Photographs showing the ERT cable construction and installation (for details see text) 


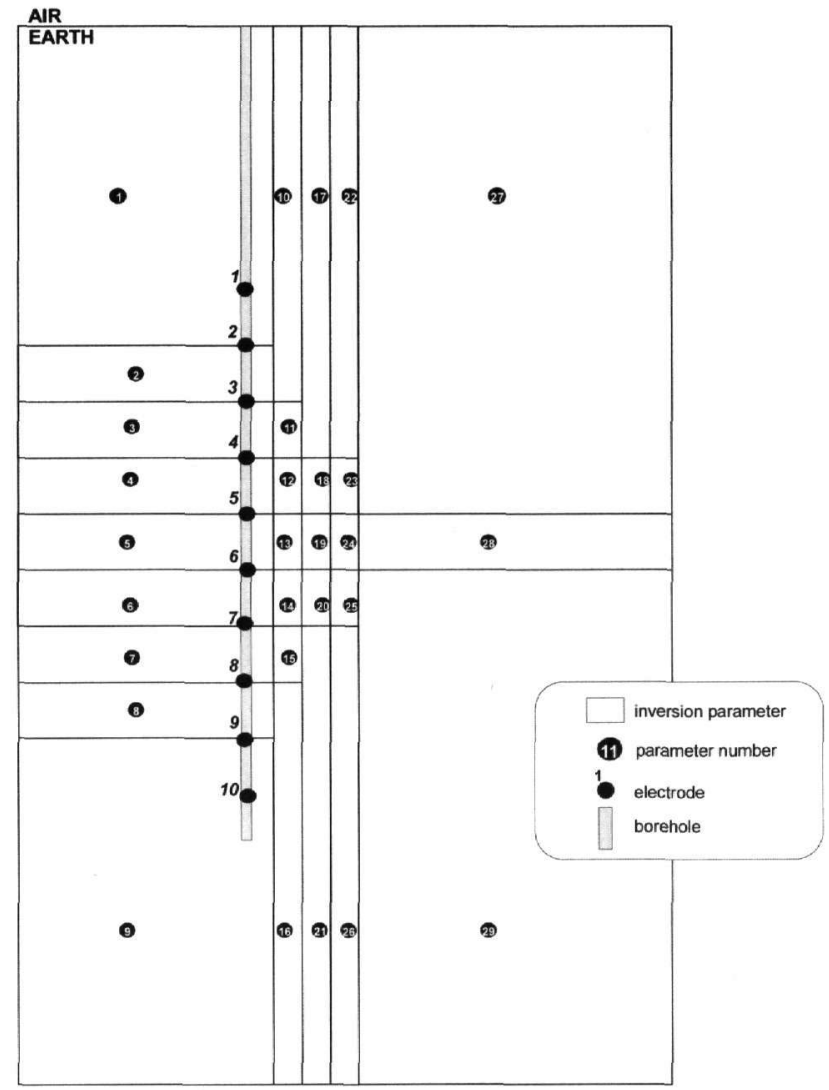

Figure 4 - An example of the applied parameterisation for the case of 10 borehole electrodes

For every borehole two data sets employing the dipole-dipole and the Wenner-Schlumberger arrays were routinely collected. Data were inverted with the described algorithm and the final inversion RMS errors were below $5 \%$ after rejecting 2-3\% of the data as outliers.

In Fig. 5 the results produced from inverting the dipole-dipole single hole data set (470 data points) from borehole $\mathrm{P} 2$ are depicted. The resistiviy section is presented in a gray scale with white colours corresponding to low resistivities and black colours to resistivity high. Generally, low resistivities, suggesting mainly clay formations, are depicted until the depth of $40 \mathrm{~m}$ followed by formations of higher resistivities corresponding to an inhomogeneous gravel and sand aquifer. The lithological column of the well is depicted as well in the figure to allow comparisons. The ERT section is in very good correlation with the lithology log: low resistivities correspond nicely to the more clayey formations while resistivity highs correspond to gravel and sand layers. ERT images seem to be sensitive even to relatively local lithology changes and most importantly provide an image of the formation up to a radial distance of $10 \mathrm{~m}$ away from the borehole. This spatial information cannot be obtained with logging or sampling.

This detailed high resolution image which is due to the fact that the sensors are now next to the formation (rather than on the surface) demonstrate clearly the advantage of this procedure compared to standard surface arrays. To further support this claim in Fig. 6 we show the inverted $500 \mathrm{~m}$ long surface ERT image obtained over the same region (P2 is at the $175 \mathrm{~m}$ of the section) using the Wenner-Schlumberger array with 21 electrodes spaced at $25 \mathrm{~m}$ intervals (see Fig. 2). Although the general picture is the same the surface ERT results are a smooth representation of the subsurface resistivity without having the detail of the borehole image. 


\section{P2}

Radial Distance (m)

$\begin{array}{lll}0 & 5 & 10\end{array}$

Resistivity
$($ Ohm-m)

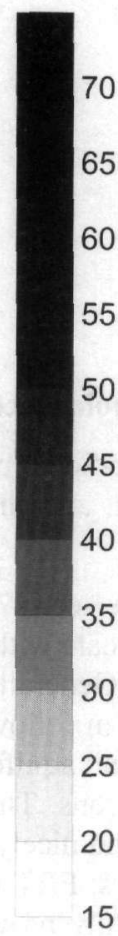

15

5

0

25

20

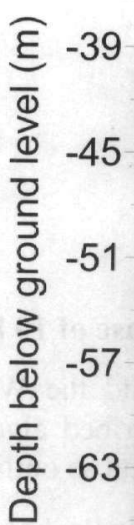

5

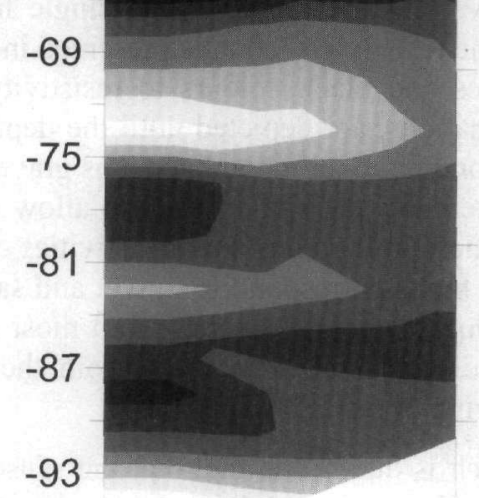

$-15$

$-18$

$-21$

$-24$

$-27$

$-30$

$-33$

$-36$

$-39$

$-42$

$-45$

$-48$

$-51$

$-54$

$-57$

$-60$

$-63$

$-66$

$-69$

$-72$

Clay and sand

$-75$

$-78$

$-81$

$-84$

$-87$

Gravel

Gravel

$-90$

Figure 5 - Single borehole inverted ERT image (left) from borehole P2 and the respective lithology log (right) 

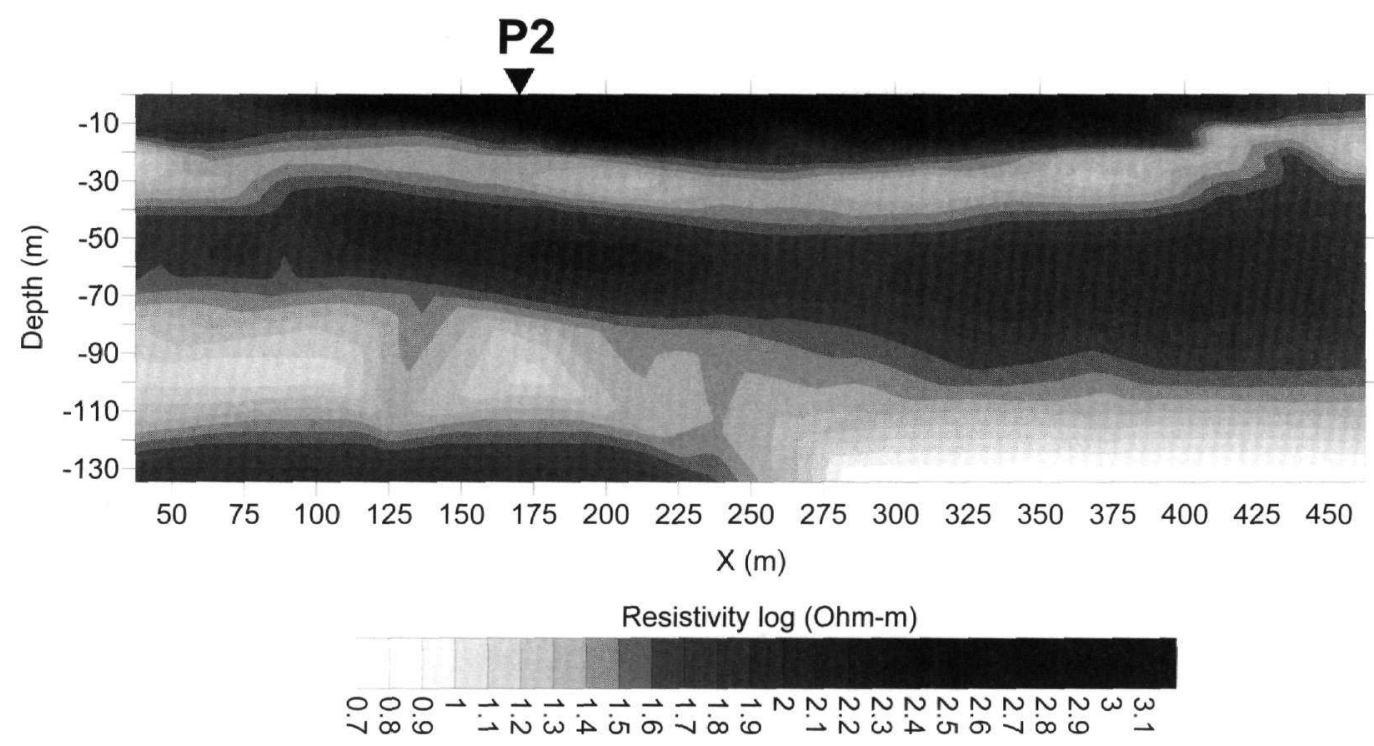

Figure 6 - Inverted ERT image of the surface array shown in Fig2

In Fig. 7 the results produced from inverting the dipole-dipole single-hole data set from P3 are depicted. The image is very similar to Fig. 5 and again the ERT section is in very good correlation with the lithology log. The relatively high resistivities at the first few meters is due to the high contact resistance that the particular borehole electrodes exhibited.

A further remark by comparing the ERT images of Figs 5 and 7 is that below the depth of $90 \mathrm{~m}$ a resistivity low can be seen. Without excluding the possibility of these being inversion induced artifacts due to edge effect the most probable explanation is that they are real given that the respective resistivity well-logs also showed low resistivities at this area. Taking into account that the lithlology does not seem to justify the resistivity low it is possible that this is due to water of higher salinity but this is left to be verified with chemical analysis of water samples and further measurements.

\section{Discussion and Conclusions}

The study shows the potential of ERT even in a single borehole mode. The cable array is easy to build, it is of low cost and can be readily installed in any PVC cased borehole. As long as it is installed it can be used to produce reliable resistivity images of the subsurface with increased resolution compared to the surface geophysical techniques.

The fact that the produced image is the "true" resistivity resulting form the inversion of numerous apparent resistivity data renders it more reliable than respective resistivity well logging tools. Further, it produces images of increased spatial information compared to point logging or sampling techniques.

The results presented here demonstrate a very good correlation of the images with the lithology logs an indication of the reliability of the approach. The permanent installation makes the application of time-lapse measurements easy and will allow the monitoring of the temporal changes into the aquifers due to the water injection. The extra application of cross-borehole and borehole-to-surface modes will provide us with reliable directional information.

Overall it is believed that the described procedure, combined with standard sampling and analysis increases the monitoring ability significantly and will help to understand and evaluate the effects of the water injection process 


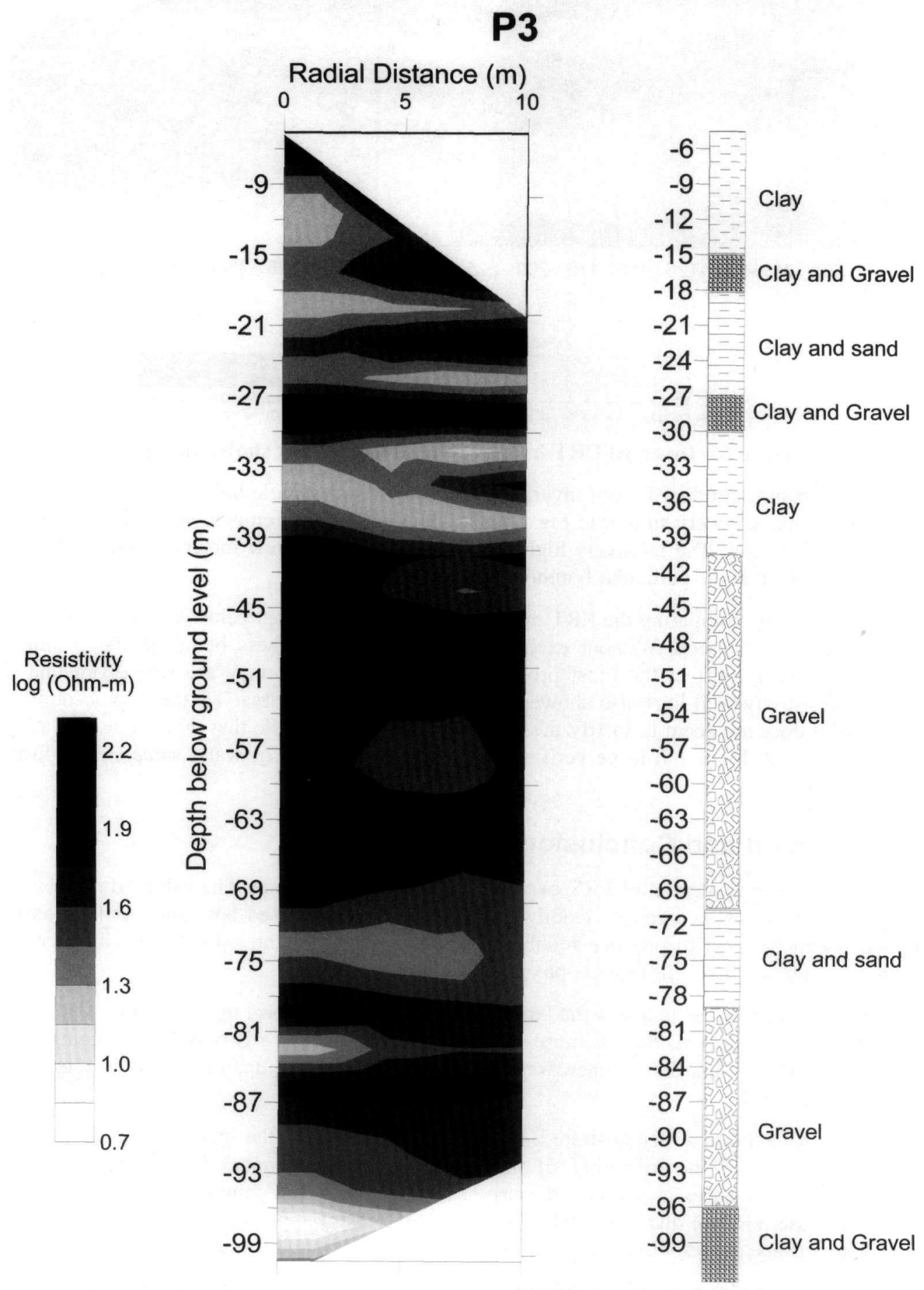

Figure 7 - Single borehole inverted ERT image (left) from borehole P3 and the respective lithology $\log$ (right) 


\section{Acknowledgements}

This work is a parallel study of the EU funded project ALERT (contract No GOCE-CT-2004505329). The support of the geophysical works by the GSRT Greek-.Korean Bilateral Collaboration Project "Borehole-To-Surface Electrical Resistivity Tomography Technology for Environmental Monitoring" is acknowledged. The authors would like to thank the Project Contractor Mr. A. Artopoulos and the drill-operator Mr Ch. Gouliamanis for their valuable help and suggestions during the cable installation process as well as several AUTH postgraduate students for their help during the field operations.

\section{References}

Asch, T.H., and Morrison, H.F., 1989. Mapping and monitoring electrical resistivity with surface and subsurface electrode arrays, Geophysics, 54, 235-244.

Bevc, D., and Morrison, H.F., 1991. Borehole-to-surface electrical resistivity monitoring of a salt water injection experiment, Geophysics, 56, 769-777.

Berryman, J.G., and Kohn, R.V., 1990. Variational constraints for electrical impedance tomography, Phys. Rev. Lett., 65, 325-328.

Daily, W., Ramirez, A., LaBrecque, D., and Nitao, J., 1992. Electrical resistivity tomography of vadose water movement, Water Resour. Res., 28, 1429-1442.

Daily, W., Ramirez, A., LaBrecque, D., and Barber, W., 1995. Electrical resistance tomography experiments at the Oregon Graduate Institute, Journal of Applied Geophysics, 33, 227-237.

Daily, W., and Ramirez, L., 2000. Electrical imaging of engineered hydraulic barriers, Geophysics, $65,83-94$.

Dahlin, T., 1996. 2D resistivity surveying for environmental and engineeringapplications, First break, 14(7), 275-283.

Ebraheem, A.M., Hamburger, M.W., Bayless, E.R., and Krothke, N.C., 1990. A study of acid mine drainage using earth resistivity measurements, Ground Water, 28, 361-368.

EEA, 1996. Requirements for Water Monitoring. Topic Report No 1/1996.

EEA, 1997. European Freshwater Monitoring Network Design. Topic report No 10/1997.

Friedel, S., Hansruedi Maurer, H., Herfort, M., and Van Meir, N., 2004. Application of singlehole geoelectrical tomography to characterize a coastal aquifer (2004), SEG Technical Program Expanded Abstracts- 2004, 620-623.

Goes, B.J.M., and Meekes, J.A.C., 2004. An effective electrode configuration for the detection of DNAPLs with electrical resistivity tomography, Journal of Environmental and Engineering Geophysics, 9,127-141.

Kim, J.-H. 2005. 4-D least-squares inversion of geophysical monitoring data: application to dc resistivity monitoring, Proceedings of the 112th SEGJ Conference Waseda University, Tokyo, Japan May 9-11, 2005, 211-214.

LaBrecque, D.J., 1989. Cross-borehole resistivity modeling and model fitting, Ph.D thesis, Univ. Utah, Salt Lake City, UT.

LaBrecque, D.J., and Yang, X., 2001. Difference inversion of ERT data: a fast inversion method for 3-D in situ monitoring, Journal of Environmental and Engineering Geophysics, 5, 8390. 
Loke, M.H., 1999. Time lapse resistivity imaging inversion, Proceedings of the $5^{\text {th }}$ Meeting of the Environmental end Engineering European, Em1, Budapest, Hungary.

Marescot, L., Palma Lopes, S., Lagabrielle, R., and Chapellier, D., 2002. Designing surface-toborehole electrical resistivity tomography surveys using the Frechet derivative, Proceedings of the $8^{\text {th }}$ Meeting of the Environmental and Engineering Geophysical Society European Section, 289-292.

Nimmer, R.E., and Osiensky, J.L., 2002. Using Mise-à -la-masse to delineate the migration of a conductive tracer in partially saturated basalt, Environmental Geosciences, 9(2), 81-87.

Morelli, G., and LaBrecque, D., 1996. Advances in ERT inverse modeling: European, Journal of Environmental and Engineering Geophysics, 1,171-186.

Park, S, 1998. Fluid migration in the vadose zone from 3-D inversion of resistivity monitoring data, Geophysics, 63(1), 41-51.

Ramirez, A., Daily, W., LaBrecque, D., Owen, E., and Chesnut, D., 1993. Monitoring an underground steam injection process using electrical resistance tomography, Water Resour. Res., $29,73-87$.

Slater, L., Binley, A.M., Daily, W., and Johnson, R., 2000. Cross-hole electrical imaging of a controlled saline tracer injection, Journal of Applied Geophysics, 44, 85-102.

Tsourlos, P., Ogilvy, R.D., Meldrum, P.I., and Williams, G.M., 2003. Time-lapse monitoring in single boreholes using electrical resistivity tomography, Journal of Environmental and Engineering Geophysics, 8, 1-14.

Tsourlos, P., Ogilvy, R.D., and Papazachos, C., 2004. Borehole-to-surface ERT inversion. In Proceedings $10^{\text {th }}$ European Meeting of Environmental and Engineering Geophysics, 6-9th September 2004, Utrecht, The Netherlands.

Tsourlos, P., Ogilvy, R.D., and Meldrum, P., 2005a. Time-lapse Monitoring using Borehole-toSurface Electrical Resistivity Tomography, Proceedings $11^{\text {th }}$ European Meeting of Environmental and Engineering Geophysics, 6-9th September 2005, Palermo, Italy.

Tsourlos, P., Ogilvy, R.D., Papazachos, C., and Meldrum, P., 2005b. Measurement and Inversion schemes for Single Borehole-to-Surface Electrical Resistivity Tomography Surveys, Near Surface Geophysics. (in press)

Yi, M.-J., Kim, J.-H., and Chung, S.-H., 2003. Enhancing the resolving power of least-squares inversion with active constraint balancing, Geophysics, 68, 931-941.

Zhou, B., and Greenhalgh, S.A., 2000. Cross-hole resistivity tomography using different electrode configurations, Geophysical Prospecting, 48, 887-912. 